\title{
Digital cultural strategies within the context of digital humanities economics.
}

\author{
Evangelos Markopoulos ${ }^{1}$, Panagiotis Markopoulos ${ }^{2}$, Mika Liumila $^{3}$, Younus Almufti $^{1}$, \\ Chiara Romano ${ }^{1}$ \\ ${ }^{1}$ HULT International Business School, 35 Commercial Road, Whitechapel, E1 1LD London \\ United Kingdom. \\ ${ }^{2}$ University of the Arts London, Elephant and Castle, SE1 6SB, London, \\ United Kingdom. \\ ${ }^{3}$ Turku University of Applied Science, Joukahaisenkatu 3, 20520, Turku, Finnland.
}

evangelos.markopoulos@faculty.hult.edu,p.markopoulos1@arts.ac.uk, mika.luimula@turkuamk.fi, yalmufti2015@student.hult.edu, cromano2015@student.hult.edu

\begin{abstract}
Staying sustainable in the world of cultural heritage is a major organizational challenge nationally and internationally. Due to the global financial crisis the funds available to sustain the operations of museums and libraries become difficult not only to obtain them but also to utilized them effectively and efficiently. The operational costs of museums increase over the time due to exhibit maintenance and acquisition costs. This cost is inversely proportional to the revenues that can be generated. Virtual reality, avatar technologies, virtual worlds, holograms, gaming and gamification can offer creative interactivity and unique experiences with low or no cost to the global visitor and introduce new revenue streams. This paper practically integrates the realization of digital cultural strategies and operations within the context of digital humanities economics that can turn museums and libraries from cost centres to profit centres for the benefit of the humanity and the society.
\end{abstract}

Keywords: Digital Museum · Digital Library - Gamification · Humanities Technology $\cdot$ Virtual Reality $\cdot$ Avatar $\cdot$ Economics

\section{$1 \quad$ Introduction}

The sustainability of the world's cultural heritage is a major issue in national and international level. The global financial crisis had also an impact on the available funds museums and libraries operations and maintenance. The limited funds that can possibly be gathered from various sources need to be spend effectively and efficiently. This situation becomes worse as the global financial crisis affects the people's ability to travel for pleasure, and even more to spend on museum visits. At the same time the operational costs of museums and libraries, of any kind, continuously increases due to the cost of the exhibit's maintenance and acquisition. This cost is inversely proportional to the revenues that can be generated. The fact that the history and cultural 
heritage of all nations is spread out in multiple museums around the world, reduces the interest of various target groups to visit a specific museum or a library. On the other hand, it is not possible to have dedicated and exclusive physical museums on specific civilizations, on all chronological periods or themes which can cover the whole spectrum of the existing exhibits globally. The Greek and the Egyptian history, for example, has been spread to hundreds of museums around the world. This impacts the Greek and Egyptian museums in terms of visitors and revenue as they operate with a small fraction of their history. The same is applied to other museums that operate with small bouquets of exbibits from different countries and civilizations, not enough to provide value to the visitor.

Under these circumstances, museums and libraries have turned out to be cost centres, living on the generosity of the donors, sponsors, corporate social responsibility programs, national and international cultural funds, etc. Museums and libraries must turn into profitable organizations not only for their sustainability but also for the secured preservation of their exhibits that contribute to the cultural heritage of the society and humanity. An inflection point on this cultural heritage preservation, dissemination and utilization equation can be achieved via the transformation of the physical museums and libraries into digital ones that can be supported by state-of-the-art technologies from other types of disciplines, industries and markets.

Virtual reality, avatar technologies, virtual worlds, holograms, gaming and gamification are only a few of the many technologies that can offer creative interactivity and unique experiences with low or no cost, to the global visitor. Based on our previous experiences virtual and augmented reality offers new ways to experience cultural context through the tools provided to create pre- and post-experiences to visitors in museums and libraries. Augmented reality in turn can be used to increase cultural experiences on-site. Even though there have been many museums already on digitization route, the actual digitization of their exhibits and artifacts is not enough. Digital operations strategy and business operations modeling must be in place to drive a museum into the digital era, and beyond.

\section{$2 \quad$ Sizing the world cultural heritage.}

Cultural heritage refers to the customs, practices, places, objects, artistic expressions and values that are passed down from generation to generation. These values can be both tangible or intangible and often refer to the way previous generations lived [1]. Ancient cultural heritage mainly manifests itself through civilizations, as they had the tendency to record their history in written form revealing a greater heritage insight. The first records of history mainly occurred in late human development period five thousand years ago in ancient civilizations such the Sumerian the Greek and the Egyptian [2]. Great civilizations are in fact difficult to track, size or value primarily due to the unfortunate impact they had from during colonization period where most of such heritage and artefacts ended up fragmented across the colonizers. The British Museum for example, holds over one hundred thousand artefacts, while the Louvre holds more than seventy thousand. Thus it is hard to track and set a certain value around these artefacts as they are associated with ambiguity when it comes to their volume, size and origin / ownership [3]. This artefact scattering needs to be carefully examined as it creates a 
challenge on sizing its value, and restricts the ability to unify not only a culture, but the global cultural heritage.

\section{Digital cultural heritage.}

Digitalization on the surface level is described as the transformation and conversion of information into a digital format, organized into a discrete form of binary data that modern devices process [4]. Digital Cultural heritage is defined as the opportunity of taking classical aspects of heritage, such as any unique resource of human knowledge and expression, and transforming them into a digital material such as texts, databases, images and other digitalization aspects [5]. Accessibility, transferability and preservability are only a few of the digitize information benefits.

Digitized cultural heritage information allows people to access it without the need of traveling around the world to experience renowned artefacts and cultural landmarks. It can further more allow access to cultural heritage from inaccessible areas. Such an example can be the rich heritage of Iraq. The country is considered today as one of the most unsafe countries to travel due to armed conflict. This situation withholds from the public. and the world as well, access to some of the most valuable heritage centres [6]. Digitization in this case can help to safely share, experience and transfer the wealth of knowledge from such heritage centres to all those who want to experience and learn from it, after all the digitized content can be a source for further and simpler education. Research indicates that the integration of technology in education can increase in learning by $12 \%$ [7]. Regarding the preservability of cultural heritage, most physical objects such as buildings, cities and even countries evolve over the time. Digitization can offer a gateway which allows access to information of such evolutions. Significant cultural heritage digitization projects are currently implemented in Egypt as part of national goals or under the UN Social Development Goals aiming to achieve digital transformation and industrial innovation that can increase the productivity in the information technology and communication sector [8].

Organizations like CULTNAT (Center for Documentation of Cultural and Natural Heritage) and the Library of Alexandria implement high impact strategic projects such towards the digitization of the Egyptian cultural heritage. CULTNAT aims to apply the latest technological innovations in documenting Egypt's tangible and intangible cultural heritage and Egypt's natural heritage, which includes information about natural areas and their biological components [9]

The project Eternal Egypt (shown in fig.1), brings to light over five thousand years of Egyptian civilization. The project is a living record of a land rich in art and history, people and places, myths and religions. The stories of Eternal Egypt are told using the latest interactive technologies, high-resolution imagery, animations, virtual environments, remote cameras, three-dimensional models and more [10].

Culturama a technology of CULTNAT (shown in fig.2), is another high impact innovation of Egypt on digital cultural heritage. It is a cultural panoramic show portraying the history of Egypt and is considered the first interactive nine-screen panorama worldwide. Culturama allows the presentation of a wealth of data layers, where the presenter can click on an item and go to a new level of details. The technology is a 
remarkably informative multi-media presentation of Egypt's heritage over 5,000 years of history up to modern times. [11]

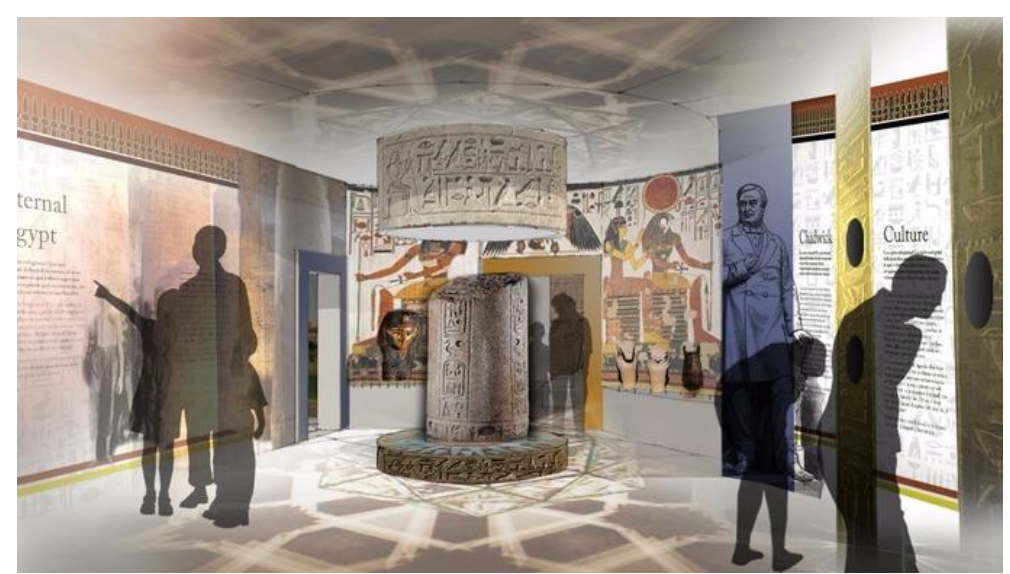

Fig. 1. Eternal Egypt.

In the same context, cultural heritage projects are developed under Virtual Reality and Augmented Reality in various ways to increase sensory and cognitive experiences for tourism. The Medieval Gastro Box developed at the Turku Game Lab in Finland (shown in fig.3) is such a case were virtual reality has been applied successfully [12]. The Turku Castle and Turku Exhibition Centre is another similar example that implemented augmented reality gamified applications for visitors to enable rich content production as a combination of digital and physical artifacts [13].

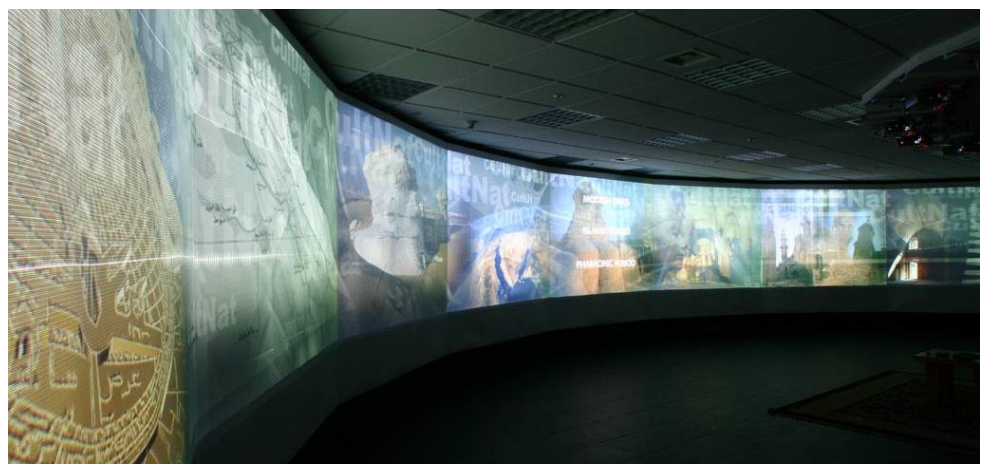

Fig. 2. Cultrama technology

Predictions today indicate a rapid grow and rise on both virtual and augmented reality market. Augmented reality has reached today the maturity needed to be practically applied in many sectors. The Pokemon Go case indicated players engagement, immersion and experiences [14]. Even that Pokemon GO was presented a few of years ago, the technology readiness level is appropriate for mass markets. However augmented reality in frequent use on cultural context has not been recorded yet. Learning 
from the Pokemon GO case, AR and VR can be applied similarly on archeological sites and cultural heritage areas to create a sense of living in places and spaces people cant walk or go.
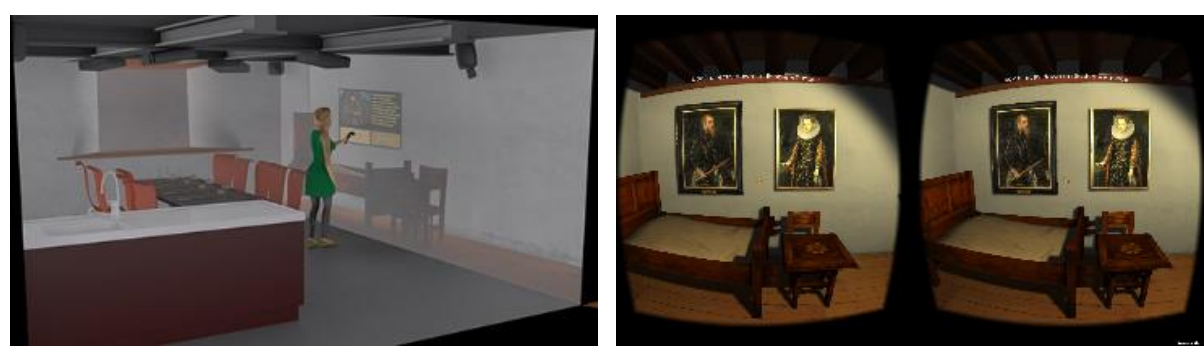

Fig. 3. Enriching sensory and cognitive experiences for tourism and hospitality industry in Medieval Gastro Box

\section{From Physical to Digital Museums and Libraries.}

Part of the cultural digitization process is the transition to digital museums and libraries as the world moves towards a digitally focused environment. Being part of cultural digitization, the digital museums and libraries can provide preservability and accessibility of highly important artefacts and books of knowledge. Digitalization of artefacts assures long term and secured preservation in the case artefacts get looted or damaged. In 2003 The Iraq National Museum was looted and 8,000 important artefacts are still lost to this day. Therefore digitization of museums also helps prevent and track objects from such instances [15]. Digital museums can also be a contribution to experts to study artefacts in a more accessible and interactive way provided that high-end technology is used to digitize them.

Utilizing the augmented reality megatrend, museums such as the Smithsonian National Museum of Natural History decided to currently combine the digitized information and the tangible artefacts, allowing viewers to use their phones to further inspect the artefacts [16]. Connectivity and convergence can be considered as another trend being utilized by digital museums and libraries. The British Museum allows now users to view museum areas through virtual reality, creating a fully immersive and digital experience without the need for the user to be there [17]. On the digital libraries end, in 2016 Egypt launched the Egyptian Knowledge Bank, one of the world biggest digital library hoping to increase productivity in research through better accessibility [18]. The Egyptian Knowledge Bank will be further expanded through national effort from Saudi Arabia, Egypt and the United Arab Emirates creating the Arab Digital Union which will merge all existing digital libraries from these countries [19].

\section{Digital Museums and Libraries Operations.}

In order to create a cultural sustainable future, museums need to take care of their assets making sure that their galleries remain valuable to future generations. Innovation has a fundamental task in making cultural heritage information accessible to everyone. 
However, it is the overall digital operations framework that needs to be defined first in that will allow the development of a relationship with the audience.

Museums need to meet and exceed the visitors' expectations by understanding their interests and identify and offer their preferred channels to interact with. According to the Museums Report by Axiell in 2016, there has been an increase of 50\% of visitor numbers due to museums' websites and a significant increase of $82 \%$ in activity on their social media platforms. Museums will have to constantly adapt to new changes in order to engage with the visitors through online channels [20] and to do that they need to do more than web-sites and on-line sales

Today the term Digital Museums mostly refer to the development of a mobile device which gives the visitors access to audio files and images throughout the tour. Users can browse the entire list of the museum through the device in order to choose the desired option; such as the number of the stop, location or artist name, brief descriptions, etc. The primary reason in developing digital museums in this sense, was to create a more sustainable and reliable approach on dealing with the entire galleries. Such an approach was considered more efficient than developing online apps which are more costly, take long time to be implemented and only a small percent of the visitors downloads them; therefore, by having a platform which empowers associates in the organisation to offer mobile tours is relatively low cost and quick, perusing a cost-effective strategy. In such applications mobile devices create and improve experiences by combining both digital and non-digital libraries.

It is essential to note that digitized collections can reach large populations and increase the interest of the users in the long run leading to a physical visit. Despite the fact that digitized collections can't replace the genuine experience of visiting a museum, their prime purpose is to make them accessible to everyone. The main operations strategies for digital museums are presented in Table 1.

Table 1. Digital museum operations strategies.

\begin{tabular}{ll}
\hline $\begin{array}{l}\text { Digital Museum } \\
\text { Strategy }\end{array}$ & Description \\
\hline Mobile Technology & $\begin{array}{l}\text { The use of mobile devices throughout a tour improves } \\
\text { knowledge to non-specialist individuals of the public. }\end{array}$ \\
$\begin{array}{l}\text { Digital content ex- } \\
\text { change }\end{array}$ & $\begin{array}{l}\text { Reduces the expenditures of digitized collections by sharing } \\
\text { the information with other museums. Visual assets are costly } \\
\text { yet can be effectively and efficiently shared between galler- } \\
\text { ies, benefiting the consumer once the data is suitably col- }\end{array}$ \\
& $\begin{array}{l}\text { lected and packaged. } \\
\text { Maintain updated the social media platforms, since they are } \\
\text { the modern channel for communication and networking. So- } \\
\text { cial media platforms allow organizations to interact with cli- } \\
\text { ents and provide a real one to one communication, giving } \\
\text { them the freedom to share their opinions, experiences or any- } \\
\text { thing they want. }\end{array}$ \\
On-line monetiza- & $\begin{array}{l}\text { Museums using online monetisation of small services and mi- } \\
\text { cro-sales, in order to increase their profit. }\end{array}$ \\
tion & $\begin{array}{l}\text { Protection of valuable artefacts by having them digitized un- } \\
\text { der various techniques. }\end{array}$ \\
\hline
\end{tabular}


Despite the opportunities digital museums can offer, the universal development of digital museums solutions is still challenging due to the lack of standardized digitalization methods for museums. There is an uncertainty between big strategic visions and daily operations in the transformation of museums and libraries [21]. Han et al. [22] have stated that a quality model is needed to implement AR applications in Urban Heritage applications based on their findings in Dublin AR project. An EU H2020 project called ViMM (Virtual Multimodal Museum) has published a manifesto for all stakeholders from industry to end-users who are interested in the cultural heritage sector. They have emphasized audience participation, the use of harnessing technologies (e.g. artificial intelligence, virtual reality and augmented reality), openness to partnerships, digitalization based on globally used standards, and sufficient contextual information [23].

Similar to digital museums, digital libraries refer to an affordable media-management framework that allows the institutions to conserve their digital assets. Users are able to see, download, and use the assets uploaded in the system. These digital libraries give access to shared shelves, providing image collections from the world's driving exhibition halls, photograph documents, scholars, and artists in an effective repository. They can be a very complete asset accessible for instructive and academic use across disciplines with numerous rare and valuable accumulations that cannot be seen somewhere else. [24]. The digital libraries can also satisfy the qualified majority of the users' requirements for digital images. They can offer access to its consistently developing collection and supply useful tools to enable users to organize and present.

The main advantage of digital libraries is that provide an easy and quick access to books, files and pictures of different types to everyone and everywhere. Digital libraries reduce the library's personnel costs and increase the potential to store much more data than a physical library and have all that accessible around the clock.

\section{Advance technologies for the operations of digital museums and libraries.}

The growth of technology in science and applications seems to be followed and adapted in the digital culture industry. The British Museum uses virtual reality to transport visitors to the bronze age. This project consists in engaging visitors with the past through virtual reality, using $3 \mathrm{D}$ headsets, tablets, and a projection of a dome structure sufficiently expansive to fit groups of five to enter. Although older generations find the VR confusing, younger audiences embrace it positively, encouraging visitors to move from the reproduced past to the genuine objects. Recent studies have shown that more than 60,000 young people have visited the museum due to the launch of virtual reality; therefore, it has expanded the enthusiasm to visit the exhibition hall [25].

Virtual reality is just one of the several digital strategies that museums can adopt to see the cultural world. The introduction of augmented reality allowed galleries to overlay instructive or entertaining content without adjusting the physical space, since realworld objects are augmented by PC produced perceptual data. It contains different sensory modalities, including visual, sound-related, haptic, somatosensory, and olfactory 
[26]. According to The New York Times, the Newseum has launched a new project using VR and AR, attracting a diverse audience including gamers.

Artificial intelligence is progressively being utilized today by historical centres of all sizes around the world, developing everything from robots, chatbots and sites, to devices that help analyse guest information and their collections. In 2018 it has been produced for the first-time humanoid robots to answer guests' inquiries and recount stories, utilizing voice, signals and an interactive touch screen. Also, they are able to dance, play games and pose for pictures. Artificial intelligence has been introduced in museums in order to engage the visitors by creating a playful and joyful experience [27].

However the use of advanced interactive technologies in digital museums and libraries open various research questions to be tackled in terms of cost-effectiveness (digital new value creation), methodology (for pre-defined preferred digital content), research methods (user centric design, rapid prototyping etc.), 3D modelling process (e.g. interoperability issues for various software platforms), commercial viability, test procedures, cultural differences, scalable business models (including business ecosystems).

\section{$7 \quad$ Examples of a gamified digital museums and libraries.}

Due to digitalization era, museums and libraries have already digital content for new value creation through various types of applications. Gaming and gamification of cultural heritage is a growing sector in the digital culture industry. Digital property can be seen as a raw material for innovative gamified solutions which can be used in any possible way. An example is the Turku Castle application which represents renaissance era paintings in a form which can serve visitors who are interested in stories behind paintings but also those who are more interested in gamified features. Both of tourist and game-mode engage a physical visit to Turku Castle (shown in fig.5) [14].
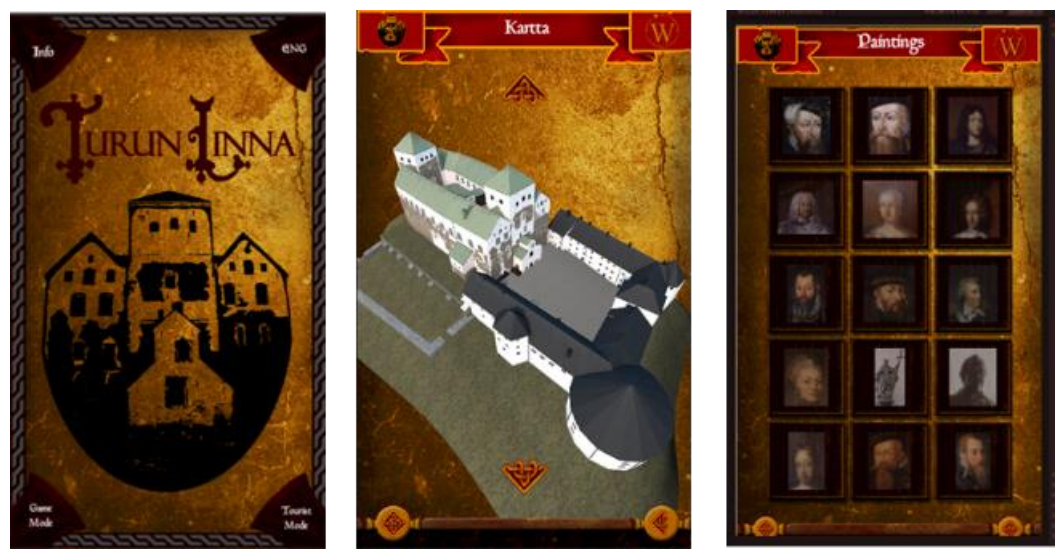

Figure 5. Digital content enables rich cultural experience.

The Turku Castle application as an example of AR applications has been extended and further developed to be suited for nearly any kind of tourism-based activity, event 
or a venue. Moreover, as the Medieval Gastro Box is located within two containers and a mobile unit, it can bring tourism related activities as a pop-up VR experience into various real-world locations, providing a new concept for many fields of tourism and hospitality industries, e.g. marketing, promotion, trade fairs and expositions.

Besides the museums VR and AR technology can also be used to promote cultural heritage in events such as exhibitions. Fair game platforms can be extended to cover for example cultural heritage topics such as Mikael Agricola (shown in fig.6) who is the author of the first book published in the Finnish language. In Mikael Agricola fair game AR was used to launch small mini games which were physically located around the exhibition center. Mikael Agricola post cards were used as visual markers for triggering mini games which were designed for pupils visiting in the exhibition as a part of their Finnish language studies.
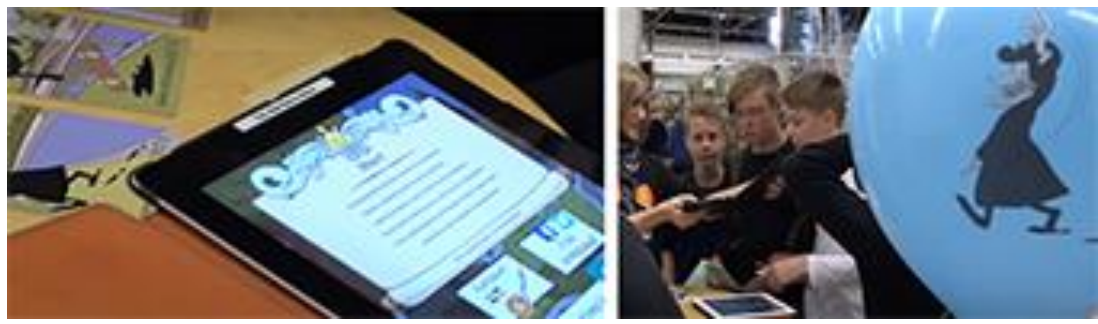

Fig. 6. Mikael Agricola fair game designed for education in cultural heritage.

VR Ships for Forum Marinum (figure 7) is in another example of VR applications developed for cultural heritage. This application gives for the museum visitor an experience of boarding the famous Finnish ships and airplanes from wartime Finland in a realistic environment with VR glasses. In this experiment, focus was on providing historically accurate ships and other relevant content. In addition, also audio and sounds have been designed based on the location of the player (submarine, airplane etc).

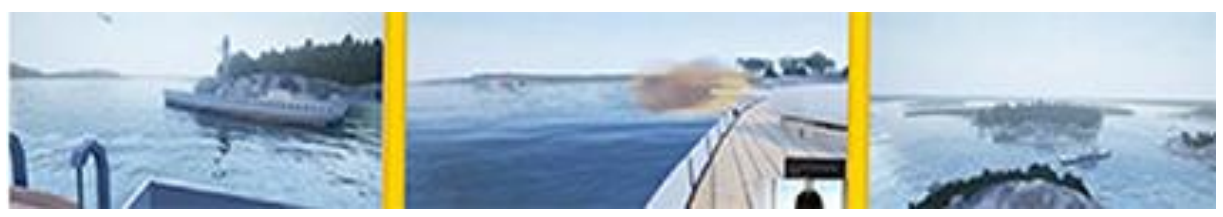

Fig. 7. VR Forum Marinum demonstration Finnish ships \& airplanes from wartime.

\section{Cultural heritage digitization funding.}

Digital libraries and digital museums compose the key areas of applications of the wider cultural heritage digitization strategies adapted by many nations globally over the last decade at least. The European Commission Directorate General for Communications Networks, Content \& Technology has conducted extensive policy, coordination as well as funding actions to supplement Member States' cultural policy in areas of digitization and online access to cultural material and digital preservation. 
Programs such as the Horizon 2020, the Interreg and others fund projects related to accessing cultural heritage through digital infrastructures, emotive virtual cultural experiences and other related initiatives [28].

On the same route the United Kingdom offers numerous funding opportunities as well. The Joseph Rowntree Charitable Trust provides funding to support cultural heritage digitization projects. The Heritage Lottery Fund (HLF) uses revenue generated from The National Lottery to provide funding for a variety of UK heritage projects, including digitization and digital archiving projects. The Wellcome Trust offers funding for the digitization of UK based archive and library collections through its Research Resources Award grant scheme. The Grant Fund supports the digitization of collections relating to the history of medicine and health, the medical humanities or social sciences. The Arts \& Humanities Research Council (AHRC) offers a number of funding streams that will support the creation of digital resources, with a variety of projects funded, including their Standard Research Grants and Follow on funding scheme [29].

Similar strategies can be found in Egypt, Mexico, China, and almost everywhere in the world. The new economy that rises around the implementation of cultural heritage projects primarily on digital museums and library, but also on managing and maintaining such digital operations cannot be ignored. Digital humanities via the digitization of the global cultural heritage reshapes the way art and knowledge is provided to the new generations, by creating new economies and new societies.

\section{$9 \quad$ Areas of further research.}

The research conducted for this paper forms the base for a more techno-economic analysis on the design, implementation, management and maintenance of digital museums, libraries and other cultural heritage and digital humanities areas of applications. The effectiveness of a digital project, especially in culture and humanities, is related to the usage it achieves and the community it creates around it. Techniques, methods and practices such as gamification, immersive education via virtual reality, augmented reality, artificial intelligences and other technologies plays a key role to the success or such initiatives. If applied properly they also assure profitability which is essential for their maintenance and continuous enhancements needed to keep on with the user trends and needs. This work will be extended on studying, in depth, the cost-benefit analysis, user engagement, return on investments, revenue streams and other techno-economic elements in order to understand furthermore the cost, time, effort and investment (in human and financial capital) needed towards making the transition from the physical to the digital culture and humanities.

\section{Conclusions.}

Digital cultural heritage and digital humanities, in a wide sense, is not anymore, a future trend but a present need. It is part of national and international digitate strategies designed and executed by nations and groups of nations over the last decade. 
The increase of globalization creates the need to unify, share and experience the global cultural heritage. This need becomes bigger in our days due to the global financial crisis which makes access to arts, humanities and culture restricted for many. Digitization seems to be a solution to these challenges, but the cost, time and effort needed to move into a digital period must be studied against the world's readiness and willingness for such a transition.

The paper indicated with examples, operations and technologies the digitization movement that takes place on museums and libraries. However, this movement is at an early stage with low maturity on both technology adaptations, awareness and dissemination. Going digital on cultural heritage is certainly the way to proceed not only for the preservation, usage and utilization of such a wealth but mostly for the evolution of the society by understanding better and deeper that we are all connected in this planet and we shall always be.

\section{References}

1. ICOMOS: International Cultural Tourism Charter. Principles And Guidelines For Managing Tourism At Places Of Cultural And Heritage Significance. ICOMOS International Cultural Tourism Committee (2002)

2. Kramer, S.: History begins at Sumer, Thirty-nine firsts in Man's recorded history. Philadelphia: The University of Pennysylvania (1990)

3. History of the collection, https://www.britishmuseum.org/about_us/departments/ancient_egypt_and_sudan/history_of_the_collection.aspx

4. WhatIs.com. What is digitization?, https://whatis.techtarget.com/definition/digitization

5. Concept of Digital Heritage | United Nations Educational, Scientific and Cultural Organization, http://www.unesco.org/new/en/communication-and-information/access-toknowledge/preservation-of-documentary-heritage/digital-heritage/concept-of-digital-heritage/

6. Iraq Travel Advisory, //travel.state.gov/content/travel/en/traveladvisories/traveladvisories/iraq-travel-advisory.html

7. Tamim, R. M., Bernard, R. M., Borokhovski, E., Abrami, P. C., and Schmid, R. F.: What forty years of research says about the impact of technology on learning. Review of Educational Research, 81(1), 4--28 (2011)

8. Egypt Digitization 2020 - A New National Digital Transformation Initiative Planned to for Egypt by Resilience, http://resilienceand.co.uk/egypt-digitization-2020-a-new-national-digital-transformation-initiative-planned-to-for-egypt-by-resilience/

9. Bibliotheca Alexandrina. Center for Documentation of Cultural and Natural Heritage (CultNat), https://www.bibalex.org/en/center/details/thecenterfordocumentationofculturalandnaturalheritagecultnat

10. Eternal Egypt, http://www.eternalegypt.org/EternalEgyptWebsiteWeb/HomeServlet?ee_website_action_key=action.display.home\&language_id $=1$

11. Bibliotheca Alexandrina Cultrama, https://www.bibalex.org/en/project/details?documentid $=295$

12. Qvist, P., Bulatovic Trygg, N., Luimula, M., Peltola, A., Suominen, T., Heikkinen, V., Tuominen, P., and Tuusvuori, O., Demo: Medieval Gastro Box - Utilizing VR Technologies in Immersive Tourism Experience, In: Proceedings of the 5th IEEE Conference on Cognitive Infocommunications, 77--78 (2016)

13.Bulatovic Trygg, N., and Luimula, M.: Cultural Heritage in a Pocket - Case Study "Turku Castle in Your Hands", In: Proceedings of the 5th IEEE Conference on Cognitive Infocommunications, 55--58. (2016) 
14.Pyae, A., Luimula, M., and Smed, J.: Investigating Players' Engagement, Immersion, and Experiences in Playing Pokemon Go. In: Proceedings of the 2017 ACM SIGCHI Conference on Creativity and Cognition, June 27-30, 2017, 247--251. (2017)

15.Fifteen years after looting, thousands of artefacts are still missing from Iraq's national museum, http://theconversation.com/fifteen-years-after-looting-thousands-of-artefacts-are-stillmissing-from-iraqs-national-museum-93949

16. Five Augmented Reality Experiences That Bring Museum Exhibits to Life., https://www.smithsonianmag.com/travel/expanding-exhibits-augmented-reality-180963810/

17. Explore ancient Egypt in our Virtual Reality tour. (2017). Retrieved from https://blog.britishmuseum.org/explore-ancient-egypt-in-our-virtual-reality-tour/

18. Egypt Launches the 'World's Biggest Digital Library'. (2016). Retrieved from http://cairoscene.com/ArtsAndCulture/Egypt-Launches-the-World-s-Biggest-Digital-Librar

19. El-Bakry, F. (2018). Egypt, KSA, UAE to share knowledge via Arab Digital union. Retrieved from http://www.egypttoday.com/Article/1/61565/Egypt-KSA-UAE-to-share-knowledgevia-Arab-Digital-union

20. Digital Transformation in the Museum Industry. Axiell ALM, 2016, alm.axiell.com/wp-content/uploads/2016/07/Axiell-ALM-Digitise-Museums-Report.pdf.

21. Leorke, D., Wyatt, D. and McQuire, S.: More than just a library: Public libraries in the 'smart city', City, Culture and Society 15, 37--44 (2018)

22. Han, D. I., Jung, T. and Gibson, A. Dublin AR: Implementing Augmented Reality (AR) in Tourism, In Z. Xiang, \& I. Tussyadiah (Eds), Information and Communication Technologies in Tourism, 511-523 (2013)

23. The ViMM Manifesto for Digital Cultural Heritage, https://www.vi-mm.eu/wp-content/uploads/2018/09/ViMM-Manifesto-Revised-Final-4-Sept.pdf

24. Artstor Digital Library. Collections from the World's Leading Museums and Archives, www.biblioteche.unical.it/banchedati/artstor_r_intro_1604.pdf.

25. The Guardian, Guardian News and Media. British Museum Uses Virtual Reality to Transport Visitors to the Bronze Age, www.theguardian.com/culture/2015/aug/04/british-museum-virtual-reality-weekend-bronze-age.

26. Museums Heritage Advisor. Technology in Museums - Introducing New Ways to See the Cultural World, https://advisor.museumsandheritage.com/features/technology-museums-introducing-new-ways-see-cultural-world/

27. The New York Times. Artificial Intelligence, Like a Robot, Enhances Museum Experience, www.nytimes.com/2018/10/25/arts/artificial-intelligence-museums.html.

28.European Commission. Digital Cultural Heritage, https://ec.europa.eu/digital-single-market/en/digital-cultural-heritage

29.Towns Web Archiving. Guide: Sources of Funding for heritage digitisation projects, https://www.townswebarchiving.com/2018/02/sources-funding-for-heritage-digitisation-projects/ 